Research article

\title{
Reporting of conflicts of interest in guidelines of preventive and therapeutic interventions George N Papanikolaou ${ }^{1}$, Maria S Baltogianni ${ }^{1}$, Despina G Contopoulos- Ioannidis $^{1,2}$, Anna-Bettina Haidich ${ }^{1}$, Ioannis A Giannakakis ${ }^{1}$ and John PA Ioannidis ${ }^{* 1,3}$
}

\author{
Address: ${ }^{1}$ Clinical Trials and Evidence-Based Medicine Unit, and Social Medicine and Public Health Unit, Department of Hygiene and \\ Epidemiology, University of Ioannina School of Medicine, Ioannina 45110, Greece, ${ }^{2}$ Department of Pediatrics, George Washington University \\ School of Medicine, Washington, D.C., USA and ${ }^{3}$ Department of Medicine, Tufts University School of Medicine, Boston, MA, USA \\ E-mail: George N Papanikolaou - vsolomou@cc.uoi.gr; Maria S Baltogianni - vsolomou@cc.uoi.gr; Despina G Contopoulos- \\ Ioannidis - me00421@cc.uoi.gr; Anna-Bettina Haidich - me00409@cc.uoi.gr; Ioannis A Giannakakis - medai@ioa.forthnet.gr; \\ John PA Ioannidis* - jioannid@cc.uoi.gr \\ ${ }^{*}$ Corresponding author
}

Published: 4 June $200 \mathrm{I}$

BMC Medical Research Methodology 200I, I:3

This article is available from: http://www.biomedcentral.com/I47/-2288/I/3

(c) 200I Papanikolaou et al, licensee BioMed Central Ltd.
Received: 5 March 200I

Accepted: 4 June 2001

\begin{abstract}
Background: Guidelines published in major medical journals are very influential in determining clinical practice. It would be essential to evaluate whether conflicts of interests are disclosed in these publications. We evaluated the reporting of conflicts of interest and the factors that may affect such disclosure in a sample of 191 guidelines on therapeutic and/or preventive measures published in 6 major clinical journals (Annals of Internal Medicine, BMJ, JAMA, Lancet, New England Journal of Medicine, Pediatrics) in 1979, 1984, 1989, 1994 and 1999.
\end{abstract}

Results: Only 7 guidelines (3.7\%) mentioned conflicts of interest and all were published in 1999 (17.5\% (7/40) of guidelines published in 1999 alone). Reporting of conflicts of interest differed significantly by journal $(p=0.026)$, availability of disclosure policy by the journal $(p=0.043)$, source of funding $(p<0.00 \mathrm{I})$ and number of authors $(p=0.004)$. In the entire database of 191 guidelines, a mere 18 authors disclosed a total of 24 potential conflicts of interest and most pertained to minor issues.

Conclusions: Despite some recent improvement, reporting of conflicts of interest in clinical guidelines published in influential journals is largely neglected.

\section{Background}

Guidelines have assumed a major role in forming practitioner and patient decisions about appropriate health care [1]. It is important that such efforts are not affected by conflicts of interest and that guidelines are transparent to such potential conflicts. This is even more significant for clinical guidelines published in influential medical journals that are likely to have a major impact upon therapeutic and preventive clinical care and public health worldwide. However, there has been no study of the reporting of conflicts of interest in guidelines published in medical journals. We undertook an evaluation of this issue in a sample of publications of clinical guidelines. 


\section{Materials and Methods}

Our study evaluated 6 prestigious medical journals that are likely to publish influential clinical guidelines. The journals were selected so as to include the 4 most extensively-cited clinical medicine interdisciplinary journals, as well as the most extensively-cited adult internal medicine journal and the most extensively-cited pediatric medicine journal according to the Institute of Scientific Information Journal Citation Report. Each selected journal received more than 20,000 citations in 1999. Thus we hand-searched the Annals of Internal Medicine, British Medical Journal (BMJ), Journal of the American Medical Association (JAMA), Lancet, New England Journal of Medicine and Pediatrics for guidelines published during 1979, 1984, 1989, 1994 and 1999. The appreciation of conflicts of interest has changed over the last 20 years and increasingly more strict policies have been adopted, especially in the 1990s. We aimed to evaluate whether this change is also reflected in a secular trend in the reporting of conflicts of interests in guideline publications. Therefore, we sampled guidelines across $5^{-}$ year intervals to cover a 20-year period. We preferred hand searching rather than computerized searches in an attempt to minimize loss of retrievals due to incomplete computerized coding. Two investigators independently hand-searched the pertinent volumes. Discrepancies were solved by a third investigator to reach consensus.

In order to reduce subjective interpretation of what constitutes a guideline publication we developed strict eligibility criteria. Eligible for the study were all articles that (I) contained in their titles, heading or abstracts (or introductory / summary paragraph when an abstract was missing) key words that were characteristic of guidelines ("guidelines" or "recommendations", "consensus [panelstatement-conference]", "clinical synthesis conference", "guidance", "policy statement", "practice parameter" and "position [paper-article-statement]"; and (II) had main focus on preventive and /or therapeutic interventions including health care delivery. We excluded papers where the main focus was on descriptive epidemiology, research design, diagnosis (diagnostic performance rather than clinical impact of diagnostic methods), risk assessment, legal issues, biology and/or pathophysiology. We specifically excluded editorials, commentaries, original randomized controlled trials, as well as systematic reviews and meta-analyses unless they were part of the guideline. Both full-length and shortened versions qualified, but comments and discussion items concerning guidelines were excluded. The last search for eligible guidelines was performed in mid-October 1999.

Data extraction, including journal, year, main subject focus, main country of origin, authorship, type(s) of interventions and funding, was performed on standardized forms. We also recorded whether conflicts of interest were mentioned at all, and if so, how much space was given for such disclosures. The amount of space given for conflict disclosure does not necessarily guarantee the completeness of disclosure or the quality of the conveyed information, but it can be used as a surrogate of the importance given to this information. This parameter has been previously used for other aspects of reporting in journal publications [2]. Finally, we recorded the nature of specific disclosed conflicts. We considered all reported conflicts of interest, financial and non-financial, that were judged to be relevant for publication by each journal. For each selected journal we examined the instructions to the authors over the last 20 years to examine if and when specific disclosure policies were available for conflicts of interest.

Using the Fisher's exact test we evaluated whether there were significant associations between characteristics of guidelines and the reporting of conflicts of interest. Analyses were conducted in SPSS 9.0 (SPSS Inc, Chicago, IL). $\mathrm{P}$-values are two-tailed.

\section{Results}

We recovered 191 publications of eligible guidelines (table 1). All the 6 selected journals specifically state in their current instructions to the authors that potential conflicts of interest should be declared, and have implemented various conflict of interest policies. Guidelines have not been specifically excluded from conflict disclosure in any of the 6 journals. All 1999 and 1994 publications in these journals were subject to conflict disclosure policies. In addition, such policies existed also by 1989 for JAMA, Pediatrics and New England Journal of Medicine.

Only 7 guidelines (3.7\%) disclosed potential conflicts of interest (table 1). The disclosure rate was 6.1\% when estimated on the basis of the 115 guidelines published when specific disclosure policies were in place. All disclosures had been made in 1999 and for this year the disclosure percentage was $17.5 \%(7 / 40)$. Reporting was also related to specific journals $(p=0.026)$, but the rate of disclosure was very low even in the journal with the highest disclosure rate (JAMA, 4/35 [11.4\%]). The country of origin, focus (therapy, prevention or both), group authorship and emphasis on medication vs. other interventions were not related to reporting of conflicts of interest ( $p=1.00,0.14,1.00$ and 1.00 , respectively) suggesting the deficiency is universal. Guidelines funded mostly by the government, universities or major professional organizations almost never reported on potential conflicts of interest while guidelines funded by private or mixed sources were more likely to disclose potential conflicts ( $p$ $<$ o.001). Among guidelines where specific authors as- 
sumed primary responsibility for writing the manuscript, reporting of conflicts of interest was more common when there were more authors $(\mathrm{p}=0.004)(\mathrm{ta}-$ ble 1).

Table I: Characteristics of practice guidelines: reporting of conflicts of interest.

\begin{tabular}{|c|c|c|c|c|}
\hline & & $\begin{array}{c}\text { Conflicts of } \\
\text { interest } \\
\text { reported } \\
\mathrm{N}=7\end{array}$ & $\begin{array}{c}\text { Conflicts of } \\
\text { interestnot } \\
\text { reported } \\
\mathrm{N}=184\end{array}$ & $\begin{array}{l}\text { Exact } \\
\text { p-value }\end{array}$ \\
\hline \multirow[t]{6}{*}{ Journal } & NEJM & 0 & 7 & 0.026 \\
\hline & JAMA & 4 & 31 & \\
\hline & Lancet & 0 & 9 & \\
\hline & Annals & 2 & 31 & \\
\hline & BMJ & I & 17 & \\
\hline & Pediatrics & 0 & 89 & \\
\hline \multirow[t]{5}{*}{ Year } & 1979 & 0 & 22 & $<0.001$ \\
\hline & 1984 & 0 & 40 & \\
\hline & 1989 & 0 & 47 & \\
\hline & 1994 & 0 & 42 & \\
\hline & 1999 & 7 & 33 & \\
\hline \multirow[t]{2}{*}{ Disclosure policy } & Yes & 7 & 108 & 0.043 \\
\hline & No & 0 & 76 & \\
\hline \multirow[t]{3}{*}{ Focus } & Therapy & 1 & 59 & 0.14 \\
\hline & Prevention & 3 & 100 & \\
\hline & Both & 3 & 25 & \\
\hline \multirow[t]{2}{*}{ Main country } & Europe & 1 & 25 & 1.00 \\
\hline & America & 6 & 159 & \\
\hline \multirow[t]{2}{*}{ Group Authorship } & Yes & 6 & 155 & 1.00 \\
\hline & No & I & 29 & \\
\hline \multirow[t]{2}{*}{ Drug Intervention ${ }^{*}$} & Yes & 2 & 50 & 1.00 \\
\hline & No & 5 & 134 & \\
\hline \multirow[t]{5}{*}{ Funding } & $\begin{array}{l}\text { Govern- } \\
\text { ment }\end{array}$ & 1 & 39 & $<0.001$ \\
\hline & Private & 2 & 9 & \\
\hline & University & 0 & 35 & \\
\hline & Othert & 1 & 98 & \\
\hline & Mixed $†$ & 3 & 3 & \\
\hline \multirow[t]{3}{*}{ Authors $\ddagger$} & $1-2$ & 1 & 30 & 0.004 \\
\hline & $3-9$ & 2 & 22 & \\
\hline & $10-17$ & 3 & 2 & \\
\hline
\end{tabular}

P-values are based on Fisher's exact test. ${ }^{*}$ emphasis placed on medications rather than on vaccines, devices, surgical interventions, nutritional interventions, counseling, screening, rehabilitation and other nonpharmaceutical interventions $\dagger$ other sources of funding include mostly professional organizations (American College of Physicians, American Academy of Pediatrics, American Medical Association); mixed source of funding is defined as a combination of two or more of the four categories of funding $\ddagger n=60$ for this analysis; 30 guidelines did not have group authorship and another 30 guidelines specified specific individuals who were primarily responsible for writing the manuscript, even if group authorship was mentioned
Table 2: Nature of potential conflicts disclosed

\begin{tabular}{ll}
\hline POTENTIAL CONFLICTS* & $\mathrm{N}$ \\
\hline & \\
Paid travel fees & $7(29 \%)$ \\
Provided consultation & $5(21 \%)$ \\
Received grants & $3(13 \%)$ \\
Received money as speakers & $3(13 \%)$ \\
Attended symposia & $2(8 \%)$ \\
Salary support & $\mathrm{I}(4 \%)$ \\
Worked for a specific company & $2(8 \%)$ \\
Contract for a research project & $\mathrm{I}(4 \%)$ \\
& \\
\hline &
\end{tabular}

Further analysis revealed that all guidelines reporting conflicts of interest dedicated less than $1 / 20$ of a page for this reason and less than $1 / 100$ of the total length of the article - with one exception where disclosure took 13 lines to report. In the entire database of 191 guidelines, a mere 18 authors disclosed a total of 24 potential conflicts of interest (table 2). The majority of the alluded items of conflict were for relatively minor issues (such as travel fees, speaker funds and consultation) while no author disclosed possessing stock in a company.

Sixty guidelines (27 of them published under explicit journal disclosure policies and 11 published in 1999) mentioned either specific authors or identified individuals within a panel who assumed responsibility for writing the manuscript. In total, 242 authors were listed in these guidelines (139 publishing under explicit journal disclosure policies and 79 in 1999 alone). Of those, only 15 authors disclosed conflicts of interest. The percentage of disclosing authors is $6.2 \%$ based on all years, $10.8 \%$ based on publications under explicit journal disclosure policies, and $19.0 \%$ based on 1999 alone. Panels of experts authored the other 131 guidelines, often with dozens of listed members or without detailed listing of contributors. In all these group-authored guidelines, only 3 members of one single panel disclosed conflicts of interest.

\section{Discussion}

Our study revealed that reporting of conflicts of interest in guidelines of healthcare interventions is probably largely neglected despite some recent improvement. Even in 1999, only 1 out of 6 clinical guidelines disclosed conflicts of interest. Reporting varied by journal. A recent study has shown that $50 \%$ of US medical journals with a circulation more than 1000 copies per issue (including, of course, all journals we searched in our study) have written policies regarding conflicts of interest [3,4]. 
Conflicts of interest may not be reported either because authors do not disclose them or because they are not published by the journals. Furthermore, cases of inconsistency between stated journal policy and practice have appeared in the recent literature [5].

It is estimated that the pharmaceutical industry in the United States spends $\$ 8000$ to $\$ 13000$ per year on each physician simply for marketing purposes $[6,7]$ and this phenomenon is probably international [8]. It is unknown how these figures should be extrapolated to field experts who are authors of clinical guidelines. More studies are needed to examine the extent of financial and other connections of experts to the industry in their field of expertise. One study [9] found that $15 \%$ of lead authors from Massachusetts publishing in 14 major biomedical journals in 1992 had at least one major potential conflict of interest, such as serving on scientific advisory boards of biotechnology firms in their state; being officers, directors or major shareholders in biotechnology firms; or being listed as inventors in a relevant patent or patent application. In all, $34 \%$ of the sampled articles had at least one author with a financial conflict of interest directly relevant to the publication [9]. The proportion might have been larger if financial interest data could have been retrieved from additional out-of-state and international connections and if more non-financial conflicts of interest could have been captured as well. In another study of authors of 70 studies of calcium channel blockers for treating cardiovascular disorders [10], 96\% of the authors of supportive studies had financial relationships with the manufacturers, as compared with $60 \%$ of neutral authors and $37 \%$ of critical authors. Only 2 of the 70 articles disclosed the authors' potential conflicts of interest. Finally, one study of faculty members at the University of California [11] found that $7.6 \%$ of investigators reported personal financial ties with sponsors of their research. Given the large heterogeneity in the policies of reporting faculty conflicts of interest [12,13], it is difficult to arrive at exact estimates of the frequency of serious competing interests in field experts.

In this study, it was not possible to determine exactly what might have been undisclosed, since the authors were sampled from all over the world and guidelines covered very diverse topics. Sorting out financial connections in a consistent fashion would have been practically impossible. Non-financial conflicts of interest would be even more intangible to the outsider. Nevertheless, one may speculate that competing interests may have been at least as common as what has been described in the other studies mentioned above. For example, the 1999 BMJ guideline about the management of hypertension [14] did not declare any competing interests. In a MEDLINE search, we were able to identify at least 66 randomized controlled trials of anti-hypertensive interventions authored by the guideline authors up to 1999 (range 1 to 34 per author). These trials evaluated a total of 27 different anti-hypertensive drugs (range o to 14 per author) in various doses and formulations and 9 other non-pharmaceutical interventions. In any case, funding of trials by the pharmaceutical industry does not mean that the investigators would be biased and it is expected that a panel of leading scientists would be able to balance on objective conclusions during the development of consensus. Still, it would have been useful to know what might have been the potential competing interests, including non-financial ones [15], of the panel members.

We found that conflicts of interest were rarely, if ever, published in clinical guideline reports funded by the government, universities or professional physician organizations. Although it may be anticipated that such sponsors may make more stringent efforts to assure objectivity in guideline development, it is still important that potential conflicts of interest of the individuals participating in the process should be acknowledged. This holds true even if group authorship is assumed. Conflicts of interest may be more worrisome when there is individual authorship. One would expect the objectivity of the guideline to be more vulnerable when only one or two individuals are authoring it. Nevertheless, the likelihood of disclosing conflicts of interest was smaller when few authors took responsibility for a guideline than when several authors were involved.

Recent studies have focused on deficiencies in the development and reporting of guidelines and have stressed the need to standardize the process $[16,17,18]$. Conflicts of interest can harm the credibility of guidelines. Competing interests may negatively influence the quality of clinical practice [19], as well as prescribing and professional behavior $[6,8]$. Even original studies [10] and cost-effectiveness analyses [20] may reach differing results depending on competing interests. Clinical guidelines are likely to be even more vulnerable to these influences.

\section{Conclusions}

Transparency, by means of disclosure of potential conflicts, could foster public trust. Such information would take minimal space to report and may help to obviate doubts regarding the integrity of clinical guidelines. Both guideline authors and journal editors should pay more attention to this important issue.

\section{Competing interests}

None declared 


\section{Acknowledgement}

Despina G. Contopoulos-loannidis and Anna-Bettina Haidich were supported in part by the General Secretariat for Research and Technology, Greece (grant PENED 99ED27-974 jointly funded with the European Union).

\section{References}

I. Woolf SH, Grol R, Hutchinson A, Eccles M, Grimshaw J: Clinical guidelines: potential benefits, limitations, and harms of clinical guidelines. BMJ 1999, 3 I 8:527-530

2. loannidis JP, Lau J: Completeness of safety reporting in randomized trials: an evaluation of 7 medical areas. JAMA 200I, 285:437-43

3. Krimsky S: Conflict of interest and cost-effectiveness analysis. JAMA 1999, 282:1474-|475

4. Glass RM, Schneiderman M: A survey of journal conflict of interest policies Presented at: the Third International Congress on Peer Review in Biomedical Publications; Prague Czech Republic. 1997

5. Angell M, Utiger RD, Wood AJ: Disclosure of authors conflicts of interest: a follow-up. N Engl J Med 2000, 342:586-587

6. Wazana A: Physicians and the pharmaceutical industry: Is a gift ever just a gift? JAMA 2000, 283:373-380

7. Randall $\mathrm{T}$ : Kennedy hearings say no more free lunch-or much else-from drug firms. JAMA I99I, 265:440-442

8. Giannakakis I, loannidis JP: Arabian nights - I00I tales of how pharmaceutical companies cater to the material needs of doctors: case report. BM/ 2000, 32 I : | 563-4

9. Krimsky S, Rothenberg LS, Stott P, Kyle G: Scientific journals and their authors' financial interests: a pilot study. Psychother Psychosom 1998, 67:194-201

10. Stelfox HT, Chua G, O'Rourke K, Detsky AS: Conflict of interest in the debate over calcium channel antagonists. $N$ Engl J Med 1998, 338:101-6

I I. Boyd EA, Bero LA: Assessing faculty financial relationships with industry: a case study. JAMA 2000, 284:2209-I4

12. Cho MK, Shohara R, Schissel A, Rennie D: Policies on faculty conflicts of interest at US universities. JAMA 2000, 284:2203-8

13. Van McCrary S, Anderson CB, Jakovljevic J, Khan T, McCullough LB, Wray NP, Brody BA: A national survey of policies on disclosure of conflicts of interest in biomedical research. $N$ Engl J Med 2000, 343: $|62|-6$

14. Ramsay LE, Williams B, Johnston GD, MacGregor GA, Poston L, Potter JF, Poulter NR, Russell G: British Hypertension Society guidelines for hypertension management I999. BMJ I999, 3 1 9:630-5

15. Horrobin DF: Beyond conflict of interest. Non-financial conflicts of interest are more serious than financial conflicts. $B M$ J 1999, 3 I 8:466 (letter)

16. Grilli R, Magrini N, Penna A, Mura G, Liberati A: Practice guidelines developed by specialty societies: the need for a critical appraisal. Lancet 2000, 355:103-6

17. Shaneyfelt TM, Mayo-Smith MF, Rothwangl J: Are guidelines following guidelines? The methodological quality of clinical practice guidelines in the peer-reviewed medical literature. JAMA 1999, 281:1900-5

18. Stross JK: Guidelines have their limits. Ann Intern Med 1999, I 3 I:304-6

19. Smith R: Beyond conflict of interest. Transparency is the key. BMJ 1998, 317:291-2

20. Friedberg M, Saffran B, Stinson TJ, Nelson W, Bennett CL: Evaluation of conflicts of interest in economic analyses of new drugs used in oncology. JAMA 1999, 282:1453-1457
Publish with BioMedcentral and every scientist can read your work free of charge

"BioMedcentral will be the most significant development for disseminating the results of biomedical research in our lifetime." Paul Nurse, Director-General, Imperial Cancer Research Fund

Publish with BMc and your research papers will be:

- available free of charge to the entire biomedical community

- peer reviewed and published immediately upon acceptance

- cited in PubMed and archived on PubMed Central

- yours - you keep the copyright

Submit your manuscript here:

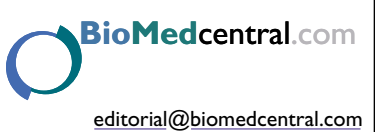

